\title{
Correspondence
}

We welcome letters to the Editor concerning articles which have recently been published. Such letters will be subject to the usual stages of selection and editing; where appropriate the authors of the original article will be offered the opportunity to reply.

Letters should normally be under 300 words in length, double-spaced throughout, signed by all authors and fully referenced. The edited version will be returned for approval before publication.

\section{Fractures of the distal radius treated by internal fixation and early function}

Sir,

We read with interest the article by Jakob, Rikli and Regazzoni ${ }^{1}$ in the April 2000 issue entitled 'Fractures of the distal radius treated by internal fixation and early function'.

This is a promising technique based on the three-column concept of the distal radius and ulna affording stable fixation and allowing early function. It is rather disturbing to note, however, that further surgery was undertaken in 21 wrists (almost 30\%) for various reasons which include rupture of the extensor tendon, extensor tendonitis and secondary displacement of the fracture. This is a high percentage and we would like to know how the authors can justify the use of this technique especially in the elderly patient.

Despite what is described as stable fixation, a loss of radial length of up to $4 \mathrm{~mm}$ and an increase in palmar tilt of up to $14^{\circ}$ are reported. Carter, Frederick and Loseter ${ }^{2}$ reported a loss of radial length of less than $3 \mathrm{~mm}$ and an increase in palmar tilt of less than $10^{\circ}$ with the use of a single low-profile plate in a multicentre study. It would seem that the double-plating technique offers no advantage in terms of stability and adds more complications.

Finally, we would have liked to see a correlation between the outcome at one year and the corresponding type of fracture (Müller classification).

S. JONES, FRCS

F. ALI, FRCS

J. FERNDANDES, MS Orth, MCh Orth

Northern General Hospital

Sheffield, UK

1. Jakob M, Rikli DA, Regazzoni P. Fractures of the distal radius treated by internal fixation and early function: a prospective study of 73 consecutive patients. J Bone Joint Surg [Br] 2000;82-B:340-4.

2. Carter PC, Frederick HA, Loseter GF. Open reduction and internal fixation of unstable distal radius fractures with a low profile plate: a multicentre study of 73 fractures. J Hand Surg 1998;23-A:300-7.

\section{Author's reply:}

\section{Sir,}

We introduced the double-plating technique for internal fixation of distal fractures of the radius in 1993 and published a preliminary

(ㄱ) 2000 British Editorial Society of Bone and Joint Surgery 0301-620X/00/811636\$2.00

J Bone Joint Surg [Br] 2000;82-B:1204-7. report on a small series in $1996 .{ }^{1}$ The technique has undergone biomechanical testing, which confirms the mechanical stability of the construct. ${ }^{2}$ Encouraged by the promising results, we used the technique more widely in patients in a prospective protocol, which is the subject of this paper. During the course of the series we encountered major complications because of technical errors (i.e., cut plate ends and incorrect placement of the dorsoradial plate). We felt a strong obligation to describe these complications in order to avoid repetition of these errors.

Of the 21 reoperations, five were due to cut plate edges and four to incorrect placement of the dorsoradial plate. Four revisions were caused by extreme distal placement of the dorso-ulnar plate because of the configuration of the fracture, which is probably encountered in other techniques. Five patients requested removal of the plate without specific symptoms; only three removals were due to irritation of the tendon. If we do not count the technical errors and the removal of the plates, we had a total of seven revisions which compares favourably with other reports.

We observed a mean loss of radial length of $1 \mathrm{~mm}$ and an increase in palmar tilt of $1.7^{\circ}$, which is in accordance with the experience of Carter et al. ${ }^{3}$ We therefore modified our design of plate and are now using one with locked distal screws to avoid this complication.

We do not claim that our technique is the sole solution to an unsolved clinical problem, but we have found it to be reliable in the management of these difficult fractures.

D. A. RIKLI, MD

Kantonsspital

Aarau, Switzerland.

1. Rikli DA, Regazzoni P. Fractures of the distal end of the radius treated by internal fixation and early function: a preliminary report of 20 cases. J Bone Joint Surg [Br] 1996;78-B:588-92.

2. Peine R, Rikli D, Hoffmann R, Duda G, Regazzoni P. Compression of three different plating techniques for the dorsum of the distal radius. $J$ Hand Surg [Am] 2000;25-A:29-33.

3. Carter PC, Frederick HA, Loseter GF. Open reduction and internal fixation of unstable distal radius fractures with a low profile plate: a multicenter study of 73 fractures. J Hand Surg 1998;23-A:300-7.

4. Ring D, Jupiter JB, Brennwald J, Büchler U, Hastings HII. Prospective multicenter trial of a plate for dorsal fixation of distal radius fractures. J Hand Surg [Am] 1997;22-A:777-84.

\section{The Stanmore total hip replacement}

Sir,

I read with interest the paper by Gerritsma-Bleeker et al. ${ }^{1}$ entitled 'The Stanmore total hip replacement' in the January 2000 issue.

In their discussion the authors state that "The longer the observation time, the more important the amount of polyethylene wear becomes", but they do not quantify the wear in their series, simply commenting that "At 22 years, eight of the 20 prostheses (40\%) showed signs of wear".

The legend accompanying Figure $3 \mathrm{~b}$ states that "no wear is seen", but there does appear to be obvious radiological penetration. The legend accompanying Figure 5b also states that "there are no signs of wear," but the actual radiological projection of the cup in this particular case makes accurate assessment of wear impossible. 
Many authors have stated that the most significant factor determining the ultimate outcome of conventional cemented total hip replacement is wear of the acetabular component. ${ }^{2}$ This is represented on plain radiographs by penetration of the metal femoral head into the polyethylene component. This penetration is the combination of two processes, creep, or cold flow, and the wear process itself, with creep having been reported to account for approximately $0.14 \mathrm{~mm}$ of the penetration.

Since the issue of wear is so crucial with regard to outcome, I would appreciate any further information on the amount of wear observed in their series, and their methods of measuring it.

D. H. SOCHART, FRCS Orth, MD

The Manchester Arthroplasty Unit, UK.

1. Gerritsma-Bleeker CLE, Deutman R, Mulder ThJ, Steinberg JDJ. The Stanmore total hip replacement: a 22 year follow-up. J Bone Joint Surg [Br] 2000;82-B:97-102.

2. Sochart DH, Porter ML. The long-term results of Charnley lowfriction arthroplasty in young patients who have congenital dislocation, degenerative osteoarthrosis or rheumatoid arthritis. J Bone Joint Surg [Am] 1997;79-A:1599-617.

\section{Authors' reply:}

Sir,

We thank Mr Sochart for his interest in our paper. Our study was principally a clinical review of the long-term results of the Stanmore hip prosthesis. We did not quantify the amount of wear, since it was not a clinical problem. We only noted the presence or the absence of significant wear. No revisions were done because of wear problems. We have had only three revisions because of aseptic loosening and one acetabular component with radiological signs of loosening in the last 12 years. Even if the amount of wear had been quantified, no significant comparison of the amount of wear between acetabular components with and without signs of loosening is possible. We noted, however, that all patients with a significant amount of wear had radiolucent lines in one or more zones around the acetabular component. We did not see osteolysis surrounding the femoral stem. A relationship between wear and loosening of the femoral stem was not found in our series.

R. DEUTMAN, MD, PhD

C. L. E. GERRITSMA-BLEEKER, MD

Martini Hospital,

Groningen, The Netherlands.

\section{Does 'canal clearance' affect neurological outcome after thoracolumbar burst fractures?}

Sir,

I read with interest the article by Boerger, Limb and Dickson ${ }^{1}$ in the July 2000 issue entitled 'Does 'canal clearance' affect neurological outcome after thoracolumbar burst fractures?'

This is a powerful, well-written article which has proved what many clinicians who have treated burst fractures non-operatively have known for a long time, that surgery makes no difference to the neurological status of these patients. Glenn Rechtine in his American Academy Lecture in 1998 eliminated the other reasons commonly used to justify such surgery in these patients. There is therefore very little excuse for surgery on burst fractures of the lumbar spine. These patients, as the authors state, can be safely managed by very early mobilisation. Given full informed consent, most should be spared the unnecessary and dangerous surgery.
Whether spinal surgeons will ignore the authors' advice remains to be seen.

D. C. JAFFRAY, FRCS Ed

The Robert Jones and Agnes Hunt Orthopaedic \& District Hospital NHS Trust

Shropshire, UK.

1. Boerger TO, Limb D, Dickson RA. Does 'canal clearance' affect neurological outcome after thoracolumbar burst fractures? J Bone Joint Surg [Br] 2000;82-B:629-35.

\section{The effect of the position of the limb on venous impulse foot pumps}

Sir,

We read with interest the paper in the April 2000 issue by Fleming et $\mathrm{al}^{1}$ entitled 'The effect of the position of the limb on venous impulse foot pumps'. Although this laboratory study assessing the Novamedix A-V impulse foot pump gave concise results, it had a number of flaws. These could mislead the development of future protocols for prophylaxis for deep-vein thrombosis.

First, the subjects in this study were all healthy and young and therefore would have had more efficient venous systems than many orthopaedic patients, who are elderly; results cannot therefore be extrapolated. Secondly, comparison of the effectiveness of the boots in the foot-up position versus the horizontal position cannot be made because only ten subjects were used. We agree, however, that the results showing the effectiveness of the footdown position are significantly different and that this is valid.

Finally, our main objection to this paper is that it recommends that patients be placed in the foot-down position when using the foot pump. This position is not always ideal in the postoperative period since hypotension, a common complication, will be exacerbated. Although it is claimed that the boot reduces swelling ${ }^{2,3}$ this has not been proven in the foot-down position. Although venous velocities are reported by the author to be increased, this does not necessarily mean that the proportion of fluid removed from the foot was higher. The study has not taken into account the increased fluid input into the limb in this position; higher venous velocities do not mean less stasis of venous blood. We suggest further investigation, possibly using plethysmography, before the foot-down position is advocated.

T. A. BARKER,

M. J. NICHOLLS

Royal Lancaster Infirmary, UK.

1. Fleming P, Fitzgerald P, Devitt A, Rice J, Murray P. The effect of the position of the limb on venous impulse foot pumps. J Bone Joint Surg [Br] 2000;82-B:433-4.

2. Gardner AMN, Fox RH, Lawrence $C$, et al. Reduction of posttraumatic swelling and compartment pressure by impulse compression of the foot. J Bone Joint Surg [Br] 1990;72-B:810-5.

3. Stranks CJ, McKenzie NA, Grover MI, Fall T. The A-V Impulse System reduces deep vein thrombosis and swelling after hemiarthroplasty for hip fractures. J Bone Joint Surg [Br] 1992;74-B:7768 .

\section{Author's reply:}

Sir,

We thank Messrs Barker and Nicholls who raise some valid points. They may, however, be trying to read more into our results than is possible. Our purpose was simply to investigate the 
hypothesis that the efficacy of the pump is improved in the footdown position. Healthy volunteers were used to try to eliminate the confounding variables of venous disease and insufficiency; and obviously such dramatic differences may not occur in elderly patients. We believe that, as a consequence of increased venous velocity in the foot-down position, there is a theoretical thromboprophylactic advantage. There will be individual circumstances, such as hypotension, in which this arrangement will be contraindicated.

Our study simply demonstrates that the position of the limb can significantly affect the efficacy of the foot pump in increasing the velocity of flow in the femoral vein; apparent differences in findings in previous studies examining the thromboprophylactic effect of the foot pump may be due to failure to take this variable into account. Further investigation is certainly required to demonstrate that the clinical benefits attributed to this device are improved in the foot-down position.

P. FLEMING, MMedSC, FRCS I

Beaumont Hospital,

Dublin, Irish Republic.

\section{Giant-cell tumour of the tendon sheath}

\section{Sir,}

We read with interest the article in the May 2000 issue by Kotwal, Gupta and Malhotra' ${ }^{1}$ entitled 'Giant-cell tumour of the tendon sheath'.

Compared with previous studies, the authors have shown an excellent reduction in the rate of recurrence with meticulous surgical excision, and an even better result in their 'high-risk' group by giving postoperative irradiation. No local complications were found in the irradiated group. They chose a group at high risk of recurrence comprising those with: 1) possible incomplete excision; 2) the presence of mitotic figures; or 3) involvement of bone. Does this mean that some of the group were actually completely excised? Is there any evidence to show that the presence of mitotic figures relates to an increased rate of recurrence if these are completely excised? Could it be that they were actually comparing two similar groups? Randomising the 'highrisk' group would have answered this question.

They concluded that postoperative radiotherapy was not indicated in cases of meticulous surgical excision although this group had a higher rate of recurrence than the high-risk group. Surely this study implies that excision and radiotherapy are preferential to complete excision, and, if so, would the authors recommend the use of postoperative irradiation for all cases of giant-cell tumour of the tendon sheath?

\section{S. J. SCOTT, FRCS}

M. D. JENKINSON, BSc

Aintree Hospital, Merseyside, UK.

1. Kotwal PP, Gupta V, Malhotra R. Giant-cell tumour of the tendon sheath. J Bone Joint Surg [Br] 2000;82-B:571-3.

\section{Authors' reply:}

Sir,

We planned to excise all the tumours completely, but in some, which had ramifications and extended into the neighbouring tissues, complete removal was difficult. The apparent incomplete excision of the tumour in six cases was therefore not deliberate.

Increased mitoses are associated with increased recurrence. ${ }^{1}$ It has been observed that three or more mitotic figures per ten highpower field represent an actively growing lesion which is likely to recur. ${ }^{2,3}$

The two groups in our study were totally different. One (34 patients) had complete excision of the tumour. The other group had either incomplete excision or increased mitoses, and therefore a high risk of recurrence.

Our results clearly indicate the beneficial effects of radiotherapy for prevention of recurrence after surgery, and we believe that this study can pave the way for a detailed randomised trial to evaluate the beneficial effects of radiotherapy.

P. P. KOTWAL, MS Orth, FIMSA

V. GUPTA, MS Orth

R. MALHOTRA, MS Orth

All India Institute of Medical Sciences

New Delhi, India.

1. Rao AS, Vigorata VJ. Pigmented villonodular synovitis (giant cell tumour of the tendon sheath and synovial membrane). J Bone Joint Surg [Am] 1984;66-A:76-94.

2. Wright CJE. Benign giant cell synovioma: an investigation of 85 cases. Br J Surg 1951;38:257-71.

3. Enzinger FM, Weiss SW. Soft tissue tumour. 3rd edition. St Louis, Missouri: Mosby, 1995:741.

\section{The teaching of trauma and orthopaedic surgery to the undergraduate in the United Kingdom}

Sir,

I read with interest the Annotation in the July issue by Williams ${ }^{1}$ on the current state of medical undergraduate education in trauma and orthopaedic surgery. Given the imminent increase in the number of students entering clinical medicine, greater focus on providing high-quality undergraduate teaching is necessary in order to achieve the standards of care expected from these future clinicians.

One possible solution would be to shift part of the responsibility of teaching to more junior orthopaedic clinicians, such as specialist registrars and senior house officers, who express an interest in and demonstrate an ability for teaching. This would not only allow these juniors to develop their teaching skills relatively early on in their training, but also ultimately free up more time for consultants to teach their own juniors as part of a structured training programme. In addition, courses such as 'Training the Trainers' at the Royal College of Surgeons, which help trainers to improve their quality of teaching, should be made available to all clinicians involved in undergraduate education.

M. RAMACHANDRAN, BSc (Hons), MB BS, MRCS

Charing Cross Hospital

Hammersmith Hospitals NHS Trust,

London, UK.

1. Williams JR. The teaching of trauma and orthopaedic surgery to the undergraduate in the United Kingdom. J Bone Joint Surg $[\mathrm{Br}]$ 2000;82-B:627-8.\$FSR\$

\section{Author's reply:}

Sir,

I thank Mr Ramachandran for his comments. I believe that the 'Training the Trainers' course has a valuable contribution to make in helping consultants and trainees to learn how to train junior doctors well. The teaching of medical students and the training of 
trainees, however, although originating from the same stem, have slightly different requirements.

Giving trainees formal training on how to teach medical students would equip them well for the time when they are consultants. It has to be noted, however, that within a six-year training programme, trainees could not be involved with the teaching of medical students on more than one session of their timetable as an isolated occurrence outside their normal clinical practice. The brunt of increased teaching demand will have to be met by the body of consultants practising within the UK.

J. R. WILLIAMS, MA, DM, FRCS Orth

The Medical School

University of Newcastle, UK

\section{At the crossroads - neonatal detection of developmental dysplasia of the hip}

Sir,

We read with interest the article entitled 'Topic for debate: At the crossroads - neonatal detection of developmental dysplasia of the hip.' 1

Both Dr Danielsson and Mr Paton have shown good results with a selective ultrasound screening programme. These results are, however, from specialised centres where the examination is done by one or, at the most, two senior experts.

These results may not be reproducible in an average district general hospital in the UK. The Trent study has shown that the outcome of total hip replacement, one of the commonest orthopaedic procedures, in such hospitals differs from the outcome in specialist centres. The same analogy can be applied to developmental dysplasia of the hips.

A recent audit of our selective ultrasound-screening programme in a distinct general hospital revealed three cases of late presentation over a one-year period. These were the consequence of failure of the clinical screening to detect 'at risk' hips. During this period there were 2846 births. Our rate of treatment over this period was 2.5 per thousand births.

While we accept that our numbers are small, the message should not be ignored. Our selective ultrasound-screening programme for 'at risk and unstable' hips failed to identify hips which would ultimately cause significant problems. Although we treated hips with a shallow acetabulum which may never have developed a problem, the 'over-treatment' with our protocol was small. Our late rate of presentation did not differ from the natural incidence of hip dislocation for our catchment population.

If such results are reflected in similar programmes across the country, it raises significant doubts regarding the value of selective ultrasound screening in a national setting.

Surely some consideration must be given to a universal screening programme as adopted by some of our European neighbours. There is concern that population screening would be impossible to implement because of poor compliance. This is a little pessimistic. If it were mandated that receipt of child benefit beyond nine weeks would not continue unless a satisfactory ultrasound screening certificate is produced, $100 \%$ compliance could be achieved. If governments can mobilise armies, surely we can put this small piece of legislation in place.

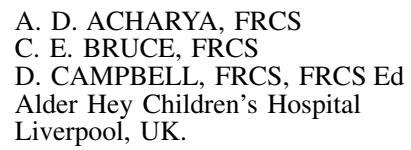

1. Jones D, Dezateux CA, Danielsson LG, Paton RW, Clegg J. Topic for debate: at the crossroads - neonatal detection of developmental dysplasia of the hip. J Bone Joint Surg [Br] 2000;82-B:160-4.

\section{Author's reply:}

Sir,

I am grateful for these focused comments. As more experience with selective ultrasound is reported, its value is increasingly suspect. I agree that the logical conclusion is to come off the fence and either screen none or all.

To carry out the former, we would have to improve our clinical skills and public awareness. For the latter, a huge mobilisation of resources would be required. I think that the authors are optimistic in suggesting that total compliance would be achieved using the examples of child benefit and conscription. I understand that child benefit is liable to be means-tested, abolished or restricted to second children onwards. There would be many appeals by those under threat of withdrawal.

Regarding the example of mobilising armed forces, not only would it be difficult to conscript an army nowadays but probably impossible to achieve compliance with mothers and lawmakers in our disparate and desperate NHS.

D. H. JONES, FRCS, FRCS Ed(Orth)

The Hospital for Sick Children

Great Ormond Street

London, UK. 